\title{
Coordination between GROWTH- REGULATING FACTOR1 and GRF- INTERACTING FACTOR1 plays a key role in regulating leaf growth in rice
}

\author{
Yuzhu Lu ${ }^{1,2,3^{*}}$, Yunlong Meng ${ }^{3}$, Jia Zeng ${ }^{3}$, Ying Luo ${ }^{3}$, Zhen Feng ${ }^{3}$, Liying Bian ${ }^{3}$ and Suyun Gao ${ }^{1,2}$
}

\begin{abstract}
Background: The interactions between Growth-regulating factors (GRFs) and GRF-Interacting Factors (GIFs) have been well demonstrated but it remains unclear whether different combinations of GRF and GIF play distinctive roles in the pathway downstream of the complex.

Results: Here we showed that OSGRF1 and OSGIF1 synergistically regulate leaf growth in rice. The expression of OsGIF1 emerged in all tissues with much higher level while that of OsGRF1 appeared preferentially only in the stem tips containing shoot apical meristem (SAM) and younger leaves containing leaf primordium. Overexpression of an OsmiR396-resistant version of MOsGRF1 resulted in expanded leaves due to increased cell proliferation while knockdown of OsGRF1 displayed an opposite phenotype. Overexpression of OsGIF1 did not exhibit new phenotype while knockdown lines displayed pleiotropic growth defects including shrunken leaves. The crossed lines of mOsGRF1 overexpression and OsGIF1 knockdown still exhibited shrunk leaves, indicating that OsGIF1 is indispensable in leaf growth regulated by OsGRF1. The expression of OsGRF1 could be upregulated by gibberellins (GAs) and downregulated by various stresses while that of OsGIF1 could not.
\end{abstract}

Conclusion: Our results suggest that OsGIF1 is in an excessive expression in various tissues and play roles in various aspects of growth while OsGRF1 may specifically involve in leaf growth through titrating OsGIF1. Both internal and external conditions impacting leaf growth are likely via way of regulating the expression of OsGRF1.

Keywords: OsGRF1, OsGIF1, miR396, Leaf growth, Stress response

\section{Background}

Interactions between transcription factors (TFs) and their coactivators are usually essential in regulating downstream genes expression and thus in properly modulating

\footnotetext{
* Correspondence: luyuzhu@yzu.edu.cn

'Jiangsu Key Laboratory of Crop Genetics and Physiology/ Key Laboratory of Plant Functional Genomics of the Ministry of Education, Yangzhou University, Yangzhou 225009, China

${ }^{2}$ Joint International Research Laboratory of Agriculture and Agri-Product Safety, the Ministry of Education of China, Yangzhou University, Yangzhou 225009, Jiangsu, China

Full list of author information is available at the end of the article
}

individual growth. Despite a wide range of genes' interactions existed in vivo, only limited numbers have been identified due to the lack of assuredly reliable methods. In plants, GROWTH-REGULATING FACTOR (GRF) and GRF-INTERACTING FACTOR (GIF) were well known to interact with each other and this complex duo has been proved to participate in many aspects of the development and growth in plants $[15,17,21,22,31]$.

OsGRF1 is the first member found to be induced by gibberellic acid (GA) in rice [43, 44]. Based on the features of OsGRF1's amino acid sequence, a family of 12

(c) The Author(s). 2020 Open Access This article is licensed under a Creative Commons Attribution 4.0 International License, which permits use, sharing, adaptation, distribution and reproduction in any medium or format, as long as you give appropriate credit to the original author(s) and the source, provide a link to the Creative Commons licence, and indicate if changes were made. The images or other third party material in this article are included in the article's Creative Commons licence, unless indicated otherwise in a credit line to the material. If material is not included in the article's Creative Commons licence and your intended use is not permitted by statutory regulation or exceeds the permitted use, you will need to obtain permission directly from the copyright holder. To view a copy of this licence, visit http://creativecommons.org/licenses/by/4.0/. The Creative Commons Public Domain Dedication waiver (http://creativecommons.org/publicdomain/zero/1.0/) applies to the data made available in this article, unless otherwise stated in a credit line to the data. 
members has been found in rice [6]. This plant-specific family was defined by two conserved domains, QLQ (Gln, Leu, Gln) and WRC (Trp, Arg, Cys), in the N-terminal region of GRF proteins. The QLQ domain is essential for protein-protein interaction [17] and WRC domain comprising a $\mathrm{C}_{3} \mathrm{H}$ motif is believed to bind DNA with its nuclear localization signal (NLS) [6]. The roles of GRFs were initially thought to regulate the growth of leaf and stem $[13,16,18,44]$. Thereafter growing number of studies reported other functions of GRFs, such as seed and root development, stress response, flowing, and plant longevity $[3,7,11,19,24,26,33]$. As a highly conserved family, GRFs have been found in all land plants including Arabidopsis thaliana, Brassica napus, Glycine max, Solanum tuberosum, Zea mays, the moss Physcomitrella patens $[2,8,19,20,27,32,46,51,53]$. Most members of GRFs are negatively regulated by miR396, which cleave their targets at the transcript level [14]. In rice, 11 of 12 members of OsGRFs are targets of OsmiR396, except OsGRF11 [40].

MiR396 was firstly identified in Arabidopsis and rice by computational and experimental means [14, 40, 49, 50]. Like GRFs, miR396 family is also a highly conserved plant microRNA family found in all land plants [1]. MiR396 has been demonstrated to be involved in various aspects of plant growth and development $[4,5,9,11,25,26,29,35-37,47]$. As a regulatory molecule, the roles of miR396 depend on the functions of its targets as well as the ways how it regulates its targets.

Compared with GRF family which usually comprises 8-20 numbers, GIF family is much smaller with only few members, usually below 5 copies, in different plants [31]. However, the phenomenon that GIF genes exist in most eukaryotic species including embryophytes, green algae, and metazoan shows this family is more conserved than GRF family [17]. The amino acid sequences of GIF are featured by having two domains, SNH (SYT Nterminal homology) and QG, which is rich of glutamine $(\mathrm{Q})$ and glycine $(\mathrm{G})$. Binding and $\mathrm{Y} 2 \mathrm{H}$ assays demonstrated that the GRF QLQ domain and GIF SNH domain mediate the interaction between the two families $[13,17,26]$. In Arabidopsis, the interactions between different AtGRFs and AtGIFs members have been well identified $[7,24,45]$. So far, it still remains unclear whether different combinations of GRF and GIF play their unique roles in the downstream of the complex. Interestingly, overexpression of ZmGRF10, which has no transactivation activity due to the lack of almost entire C-terminal domain, was found to fine-tune the homeostasis of the GRF-GIF complex via way of competitive combination [48]. Also, different combinations of GRFs and GIFs have been observed in the different regions of maize leaf [30]. These results showed that the combinations between different members of GRFs and GIFs are widely existed and in a competitive way.
Here we probed into the precise titration relationship between OsGRF1 and OsGIF1. By analyzing their expression and the phenotypes of the transgenic lines, we proposed a coordinated relationship between them.

\section{Results}

\section{Different expression patterns of OsGIF1 and OsGRF1}

Although the interactions between different GRFs and GIFs have been well tested ([13, 17, 21]; Lee et al.,2014 [26];), the precise functions of different combinations still remain unclear. There are 12 members of OsGRF and 2 members of OsGIF in rice (Oryza sativa ssp. japonica, $[6,34])$. Earlier studies revealed that OsGRF1 is a GA induced gene and can affect the stem elongation in Arabidopsis [6, 43, 44]. The functions of OsGIF1 have been reported to be involved in regulating growth of multiple organs such as leaves, stems and grains $[10,23]$. Investigating genes expression patterns is necessary for probing into their functions because genes expression patterns are usually consistent with their roles. Here, we chose OsGRF1 and OsGIF1 as objectives to fully investigate their expression profiles. We selected flowers from the adult plants and different older and younger tissues such as leaves, stems, and roots from 4-week-old seedlings as objects for analyzing genes expression. Quantitative Reverse Trancription-PCR (qRT-PCR) showed that the expression levels of OsGRF1 were relatively higher in the younger tissues including younger leaves, shoots, and roots, especially in shoot apical meristem (SAM) and leaf primordium (Fig. 1a). By contrast, the expression of OsGIF1 seemed to be constitutive with similar levels in almost all tested tissues (Fig. 1a).

qRT-PCR may show the expressional tendencies of OsGRF1 and OsGIF1 in different tissues, but cannot reflect the intensity differences of the expressions. To further compare their expression level, especially for the intensities between OsGRF1 and OsGIF1, we measured the two genes' expression by northern blot. We elaborately employed two probes containing same content of radioactively labeled $\alpha-{ }^{32} \mathrm{P}-\mathrm{dCTP}$ which was inserted into probes by PCR for hybridizing the two genes respectively. As Fig. 1b shown, the RNA abundance of OsGIF1 was much higher than that of OsGRF1 in all tested tissues, even in younger leaves and shoots where the expression levels OsGRF1 were also relatively higher. Overall, the expression levels detected by northern blot and qRT-PCR were consistent with each other (Fig. 1a and b). These results indicated that the expression of OsGIF1 is in a constitutive manner with much higher level, however, the expression of OsGRF1 displays a tissue-specific preference with relatively lower level. To further investigate the two genes expression on protein level, total protein was extracted from 2-week-old seedlings and was immunoblotted by anti-OsGIF1 and anti-OsGRF1 respectively. 


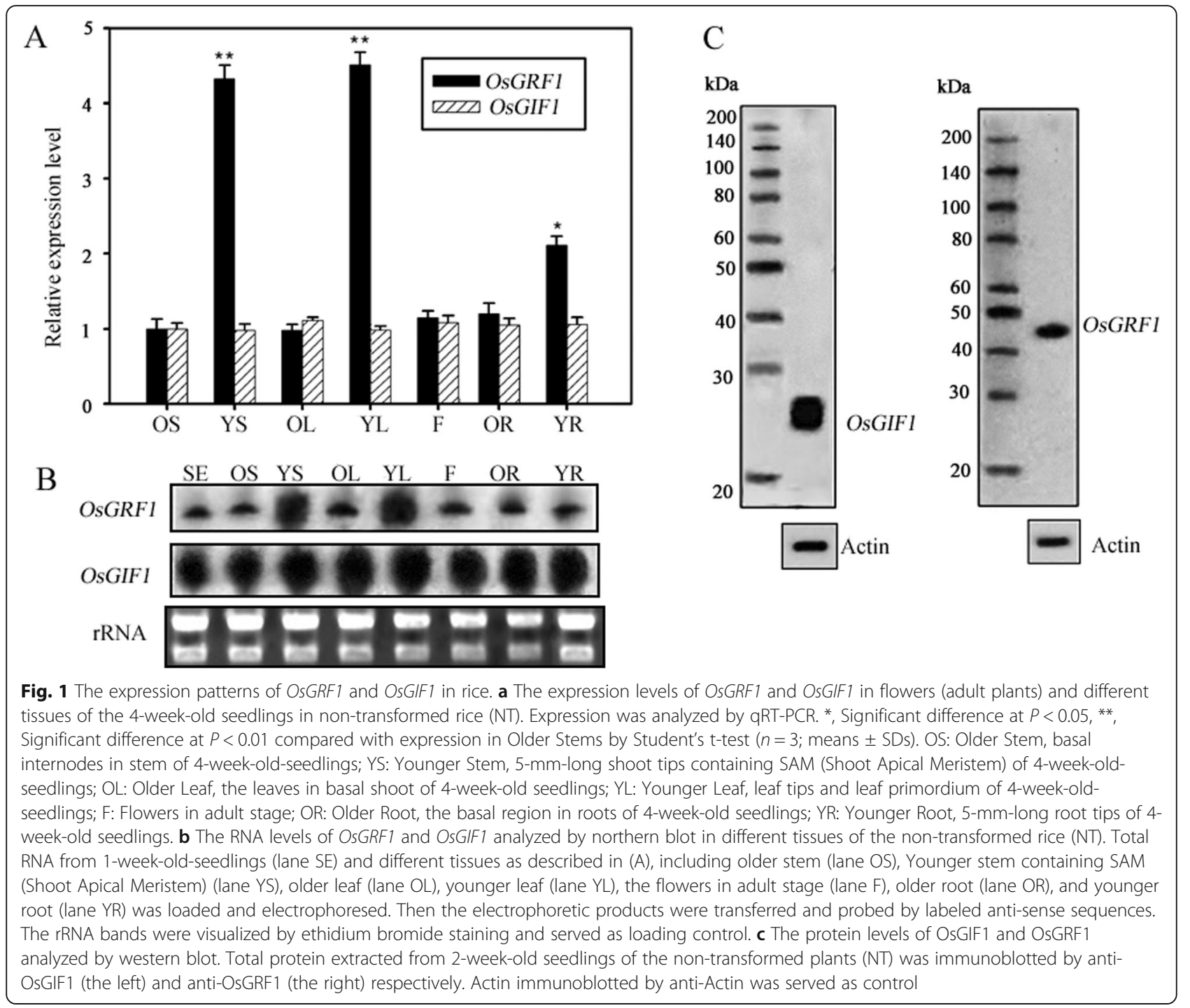

The molecular weight of the OsGIF1 was about $25 \mathrm{kDa}$ while that of the OsGRF1 is about $43.5 \mathrm{kDa}$. As shown in Fig. 1c, the blot intensity of OsGIF1 was much stronger than that of OsGRF1, further indicating the protein abundance OsGIF1 was more abundant than OsGRF1.

\section{The expression of OsGRF1 can be regulated by} phytohormones and stresses while that of OSGIF1 cannot It is well known that the OsGRF1 and most other OsGRFs are GA-inducible [6, 43, 44]. As a kind of basic plant hormone, gibberellins (GAs) are often in a pivotal hub of different pathways. Usually the concentration of endogenous gibberellins is likely affected by other factors, such as biotic and abiotic stresses [42]. Additionally we did not know whether or how OsGRF1 and OsGIF1 respond to these factors. We chose 2-week-old seedlings exposed to different treatments including GA, salt, drought, UV, pathogen, and $A B A$ for designated time. Then the total RNA from these seedlings was extracted and the two genes' expressions were measured by qRTPCR respectively. As expected, the expression of OsGRF1 was gradually increased with the extension of $\mathrm{GA}_{3}$ treatment, while that of OsGIF1 was not affected during the identical period (Fig. 2a). By contrast, the expressions of OsGRF1 were gradually reduced under the treatments of $\mathrm{ABA}$ and various stresses (Fig. 2b to f). Similar as GA treatment, the expressions of OsGIF1 were also unaffected in the other treatments (Fig. 2). Interestingly, the variation of OsGRF1 expression under ABA treatment was more remarkable than other stresses, and the expression of OsGIF1 was also slightly fallen under ABA treatment (Fig. $2 b$ to $\mathrm{f}$ ), indicating that $\mathrm{ABA}$, one of stresses-associated hormones, may have a rapid effect upon the genes' expression than other 

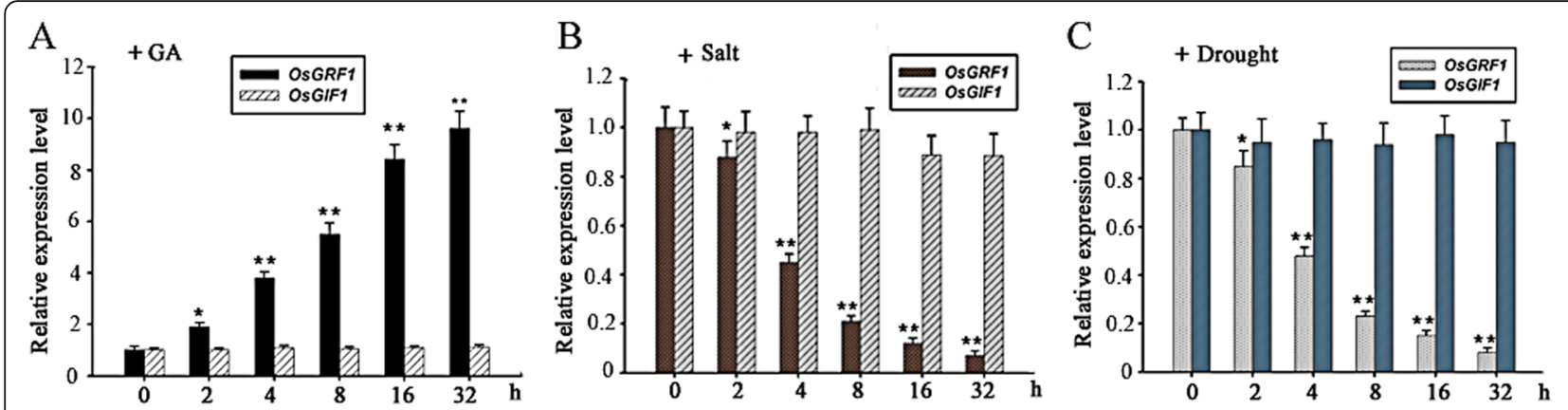

$\mathrm{D}$

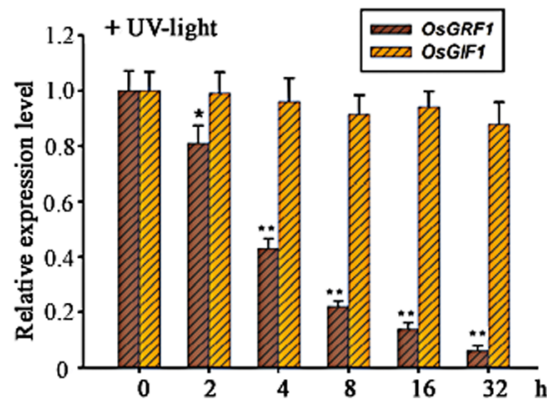

E

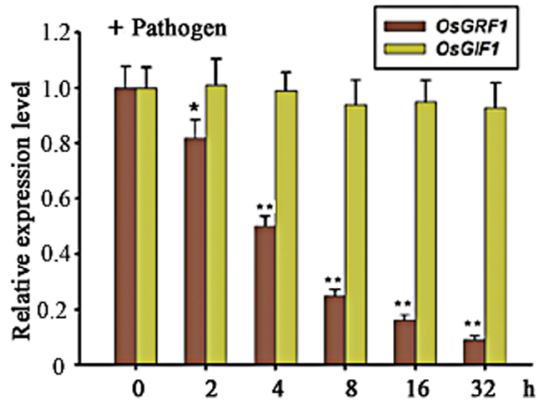

$\mathrm{F}$

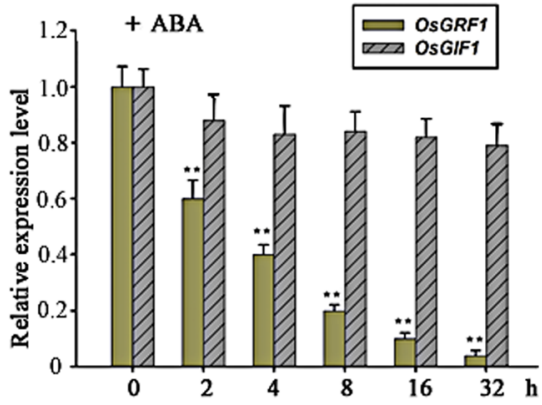

Fig. 2 Response of OsGRF1 and OsGIF1 to GA, ABA, and stresses. Time course analysis of expressions of OsGRF1 and OsGIF1 in response to gibberellins (GA), salt, drought, UV-light, pathogen, and ABA. 2-week-old seedlings were incubated into N6 solution containing $50 \mu \mathrm{M}$ GA 3 (a) or $200 \mathrm{mM} \mathrm{NaCl}$ (b) or 1 MM ABA (F) for designed time. 2-week-old seedlings were transplanted into 25\% PEG (polyethylene glycol) (c), or exposed to $100 \mu \mathrm{mol} \mathrm{m} \mathrm{m}^{-2} \mathrm{~s}^{-1}$ ultraviolet (d), or sprayed with $3 \times 10^{5}$ spore $\mathrm{ml}^{-1}$ Magnaporthe grisea (e) for designated time respectively. Expression was analyzed by qRT-PCR. * , Significant difference at $P<0.05$, ${ }^{* *}$, Significant difference at $P<0.01$ compared with No treatment by Student's t-test $(n=3$; means \pm SDs $)$

stresses. These results showed that the expression of OsGRF1 could be regulated by various factors, but that of OsGIF1 could not.

\section{Overexpression of miR396-resistant version of OsGRF1 results in expanded leaves}

OsGRF1 has already been identified as the target of miR396 in plants $[14,15,40]$. A gain-of-function mutant overexpressing a microRNA-resistant-version of target has been used for elucidating the roles of a given microRNA (Axtell and [1]). OsGRF1 was found to be highly expressed in shoot tips and young leaves (Fig. 1), indicating it likely plays role in regulating the growth of leaf and shoot. To avoid being targeted by OsmiR396, we got a miR396-resistant-version of OsGRF1 by mutating five bases of OsGRF1 mRNA in miR396-acted region without alteration of amino acid sequence according to the degeneracy of codons (Fig. 3a). Then we introduced miR396-resistant-version of OsGRF1 (named as $m O s G R F 1$ ) and wild-type OsGRF1 into rice respectively, both were driven by the native promoter of OsGRF1. The transgenic plants were propagated and the homozygous lines were selected on hygromycin in $\mathrm{T}_{2}$ generation. Northern blot and qRT-PCR showed that the RNA abundance of miR396 was nearly at same level in 4week-old seedlings of the non-transformed plants, OsGRF1OE and mOsGRF1OE, but the OsGRF1 mRNA levels in $m O s G R F 1 O E$ lines were significantly higher than that of the other two lines (Fig. 3b). The overall growth rates of the three genetic backgrounds are close to each other but an overgrowth of leaves was observed in $m O s G R F 1 O E$ lines (Table 1). The first leaf of seedlings in both wild type and OsGRF1OE was an incomplete leaf of which shape likes a needle, whereas that of $m O s G R F 1 O E$ lines had a tongue-like shape with a leafstalk (Fig. 3d). The sizes of other leaves of $m O s G R F 1 O E$ lines were also bigger than that of the non-transformed plants and OsGRF1OE in the 3-week-old seedlings (Fig. 3c). Besides these, no other obvious difference of characteristics was observed in the three backgrounds. These results showed that OsGRF1 plays roles in promoting the leaf growth. It is intriguing that $m O s G R F 1 O E$ lines had no apparent difference in stem growth even though mRNA of OsGRF1 also highly accumulated in the stem (Fig. 1). We speculated that overexpression of only one member of this family in shoot tips where all 12 members are highly expressed [6] might not be sufficient to produce an apparent stem elongation. 


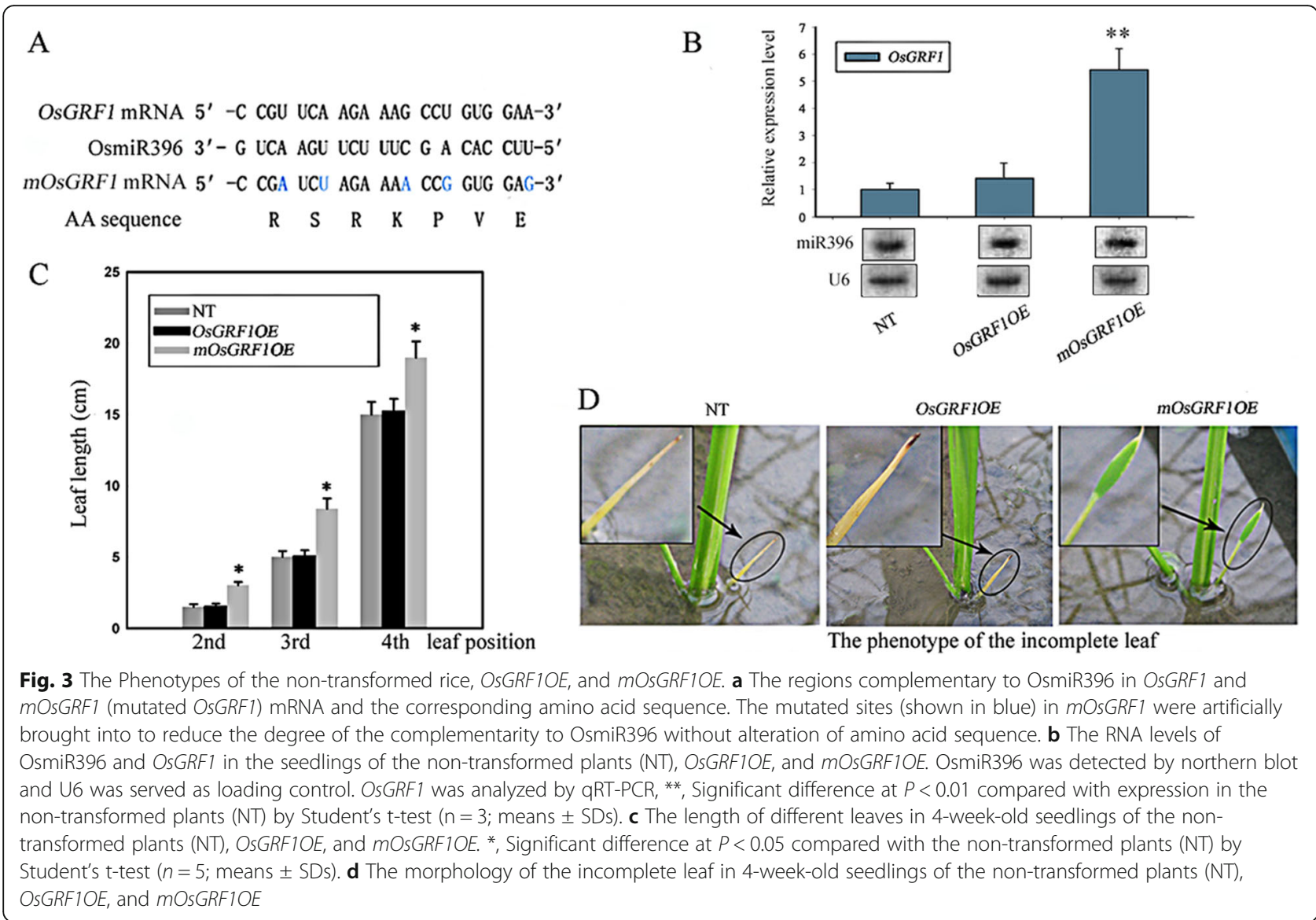

\section{Knockdown of OsGRF1 by RNAi displays a phenotype of shrunken leaves}

To further investigate the roles of OsGRF1 in rice development and growth, we knocked down OsGRF1 by RNAi (RNA interference) technology. We chose a specific sequence corresponding to 3' region of OsGRF1 as object to construct RNAi vector and brought it into rice by Agrobacterium-mediated transformation. As shown in
Fig. 4a, the expression of OsGRF1 measured by qRTPCR was significantly lower in the OsGRF1RNAi lines. The most prominent phenotype of knockdown of OsGRF1 was that the transgenic lines exhibited smaller leaves (Fig. 4b). The differences between leaf sizes of the three genetic backgrounds (NT, mOsGRF1OE, OsGRF1RNAi) were more remarkable in the position closer to the base (Fig. 4b, Table 1). To investigate

Table 1 Comparisons of the leaf phenotypes of the non-transformed plants, OsGRF1OE and mOsGRF1OE as well as OsGIF1RNAi lines ${ }^{a}$

\begin{tabular}{|c|c|c|c|c|}
\hline & $\begin{array}{l}\text { Length and width of the first } \\
\text { leaf }(\mathrm{cm})\end{array}$ & $\begin{array}{l}\text { Length and width of the } \\
\text { second leaf }(\mathrm{cm})\end{array}$ & $\begin{array}{l}\text { Length and width of the third } \\
\text { leaf }(\mathrm{cm})\end{array}$ & $\begin{array}{l}\text { Length and width of the } \\
\text { fourth leaf }{ }^{b}(\mathrm{~cm})\end{array}$ \\
\hline $\begin{array}{l}\text { Non-transformed } \\
\text { plants }^{c}\end{array}$ & $\begin{array}{l}0.54 \pm 0.06(\mathrm{~L}) \\
0.11 \pm 0.01(\mathrm{~W})\end{array}$ & $\begin{array}{l}1.51 \pm 0.19(\mathrm{~L}) \\
0.21 \pm 0.03(\mathrm{~W})\end{array}$ & $\begin{array}{l}5.03 \pm 0.40(\mathrm{~L}) \\
0.51 \pm 0.04(\mathrm{~W})\end{array}$ & $\begin{array}{l}15.00 \pm 0.88(L) \\
0.81 \pm 0.06(W)\end{array}$ \\
\hline OsGRFIOE ${ }^{\mathrm{C}}$ & $\begin{array}{l}0.6 \pm 0.05(\mathrm{~L}) \\
0.13 \pm 0.01(\mathrm{~W})\end{array}$ & $\begin{array}{l}1.60 \pm 0.15(\mathrm{~L}) \\
0.23 \pm 0.03(\mathrm{~W})\end{array}$ & $\begin{array}{l}5.50 \pm 0.5(\mathrm{~L}) \\
0.56 \pm 0.04(\mathrm{~W})\end{array}$ & $\begin{array}{l}15.5 \pm 0.77(\mathrm{~L}) \\
0.86 \pm 0.05(\mathrm{~W})\end{array}$ \\
\hline mOsGRF1OE & $\begin{array}{l}0.91 \pm 0.07(\mathrm{~L}) * \\
0.31 \pm 0.015(\mathrm{~W}) *\end{array}$ & $\begin{array}{l}3.11 \pm 0.22(\mathrm{~L}) * \\
0.40 \pm 0.04(\mathrm{~W}) *\end{array}$ & $\begin{array}{l}8.41 \pm 0.71(\mathrm{~L}) * \\
0.70 \pm 0.06(\mathrm{~W}) *\end{array}$ & $\begin{array}{l}19.02 \pm 1.12(\mathrm{~L}) * \\
1.1 \pm 0.9(\mathrm{~W})\end{array}$ \\
\hline $\begin{array}{l}\text { OsGIF1RNAic } \\
\text { mOsGRFIOE } \\
\times \\
\text { OsGIF1RNAic }\end{array}$ & $\begin{array}{l}0.33 \pm 0.04(\mathrm{~L})^{*} \\
0.07 \pm 0.01(\mathrm{~W})^{*} \\
0.37 \pm 0.05(\mathrm{~L})^{*} \\
0.08 \pm 0.01(\mathrm{~W})^{*}\end{array}$ & $\begin{array}{l}0.85 \pm 0.15(\mathrm{~L}){ }^{*} \\
0.16 \pm 0.02(\mathrm{~W}){ }^{*} \\
0.91 \pm 0.12(\mathrm{~L}) \\
0.17 \pm 0.03(\mathrm{~W})\end{array}$ & $\begin{array}{l}3.8 \pm 0.35(\mathrm{~L})^{*} \\
0.41 \pm 0.04(\mathrm{~W}) * \\
4.1 \pm 0.41(\mathrm{~L})^{*} \\
0.48 \pm 0.04(\mathrm{~W}) *\end{array}$ & $\begin{array}{l}13.20 \pm 0.65(\mathrm{~L}){ }^{*} \\
0.72 \pm 0.05(\mathrm{~W}) * \\
13.90 \pm 0.81(\mathrm{~L}){ }^{*} \\
0.81 \pm 0.04(\mathrm{~W})^{*}\end{array}$ \\
\hline
\end{tabular}

\footnotetext{
${ }^{a}$ Values are $\mathrm{n} \pm \mathrm{SD}$
}

${ }^{b}$ Statistical data are come from 3-week-old seedlings and the width presented to the widest section of leaves. $L$ in brackets indicated the length and $W$ in brackets indicated the width

c Seven plants of each genetic background were analyzed

* Means Significant difference at $P<0.01$ compared with the leaf data of non-transformed plants by Student's t-test ( $n=7 ;$ means \pm SDs) 


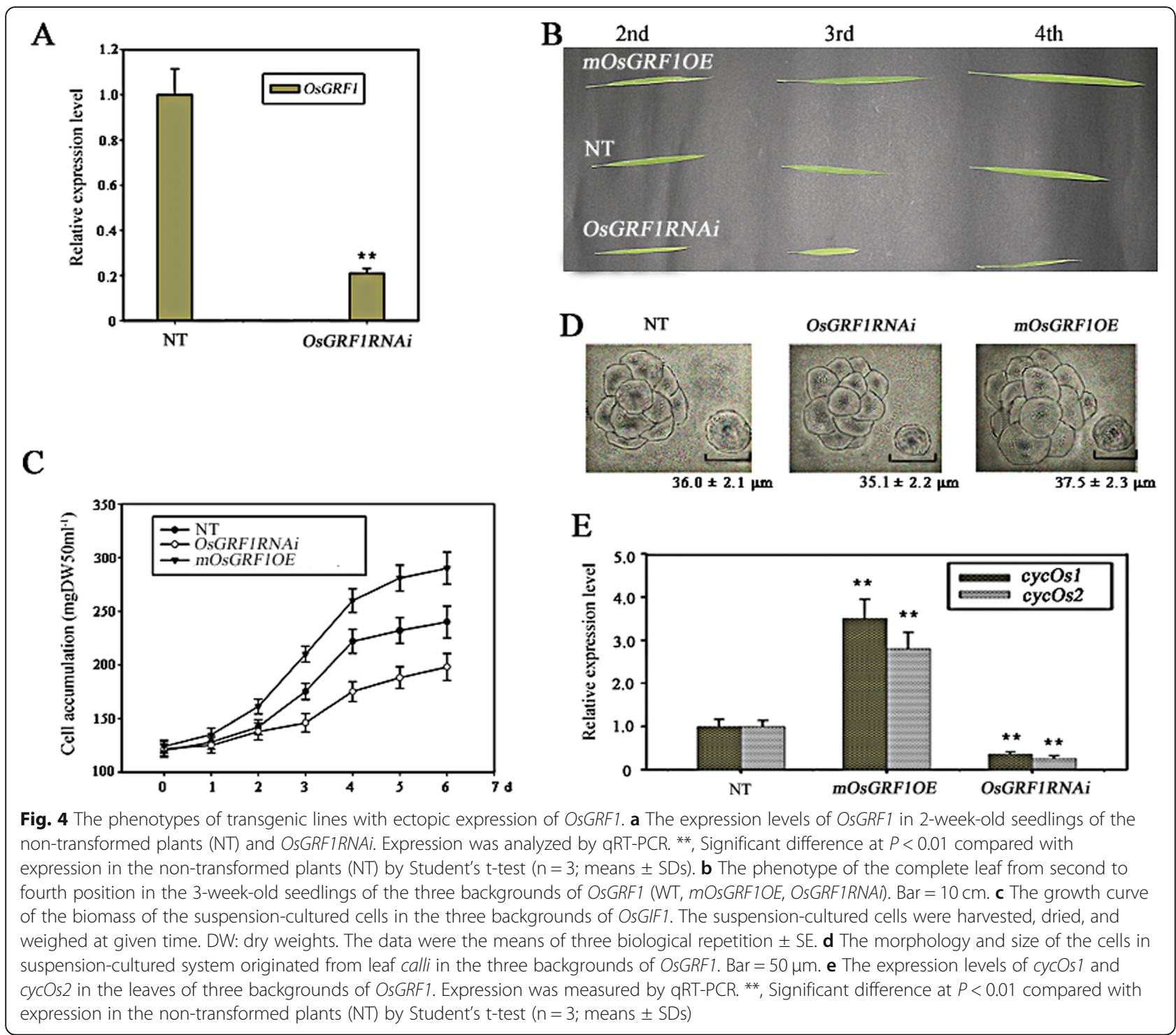

whether the difference in leaf growth was caused by cell proliferation or cell elongation, suspension-cultured cells stemmed from leaf calli of the three genetic backgrounds of OsGRF1 were made. Plants suspension systems usually are made up of numerous lumps in which dozens cells clump together, and very few dissociated cells can be observed in suspension-cultured system. After 6 days of being cultured, the biomass increment of suspensioncultured cells of OsGRF1RNAi lines was significantly lower than that of the non-transformed plants, while that of $m O s G R F 1 O E$ lines was remarkably higher (Fig. 4c). Additionally, there were no significant differences in the size of dissociated cells between the three genetic backgrounds (Fig. 4d). These results showed that the bigger differences of the leaf size between the three genetic lines are like caused by the activities of cell diversion rather than cell elongation. Some cell-cycle-related genes such as cyclin Oryza sativa1 (cycOs1), cyclin Oryza sativa2 $($ cycOs2) have been believed to be GA-induced [38, 39] even though it remained unknown whether these cellcycle-related genes were related with OsGRF1. We measured the expressions of $c y c O s 1$ and $c y c O s 2$ in the leaves of 3-week-old seedlings of the three backgrounds of OsGRF1. As shown in Fig. 4e, the expressions of cycOs1 and $c y c O s 2$ are upregulated in lines of $m O s G R F 1 O E$ and downregulated in lines of OsGRF1RNAi. These results fully demonstrated the activities of cell division could be affected by OsGRF1 in rice leaf.

Knockdown of OsGIF1 exhibits pleiotropic growth defects including shrunken leaves while overexpression shows no variation

To investigate the functions of OsGIF1 in rice, we made transgenic lines with overexpression or knockdown 
(RNAi by specific sequence) of OsGIF1. Then OsGIF1 expression levels were measured by qRT-PCR in the three backgrounds (NT, OsGIF1OE, OsGIF1RNAi) (Fig. 5b). Expectedly, the expression of OsGIF1 was significantly higher in OsGIF1OE lines while much lower in OsGIF1RNAi lines (Fig. 5b). Then the growth traits were carefully investigated during the whole lifetime. The plants overexpressing OsGIF1 did not display any new phenotype all the time in their life cycle (Fig. 5a). Their stem length, tiller number, leaf size, and thousand-grain weight, are identical to the nontransformed plants (Fig. 5a). However, the knockdown lines of OsGIF1 displayed multiple defects in their lifecycle, such as shorter stems, withered seeds, slender roots with reduced number, and shrunk leaves (Fig. 5c to e; Table 1). We had previously shown that the expressions of $c y c O s 1$ and $c y c O s 2$ could be affected by OsGRF1 in the leaves (Fig. 4e), but we did not know whether this impact needs the partner of OsGIF1. To determine this uncertainty, the expressions of $c y c O s 1$ and $c y c O s 2$ were also measured by qRT-PCR in the leaves of the three genetic backgrounds of OsGIF1. As shown in Fig. 5g, the expressional levels of $c y c O s 1$ and $c y c O s 2$ were significantly lower in OsGIF1RNAi lines while did not change apparently in the OsGIF1OE lines (Fig. 5g). These results indicated the activity of cell division was inhibited in the leaves of the knockdown lines. For the reason why the expressions of $c y c O s 1$ and $c y c O s 2$ were not changed in the lines with overexpression of OsGIF1, we speculated that the expressions of $c y c O s 1$ and $c y c O s 2$ are under control of OsGIF1-OsGRF1 duo in which the expression of OsGIF1 is already in an excessive state in the non-transformed plants (Fig. 1b and c). This assumption was further

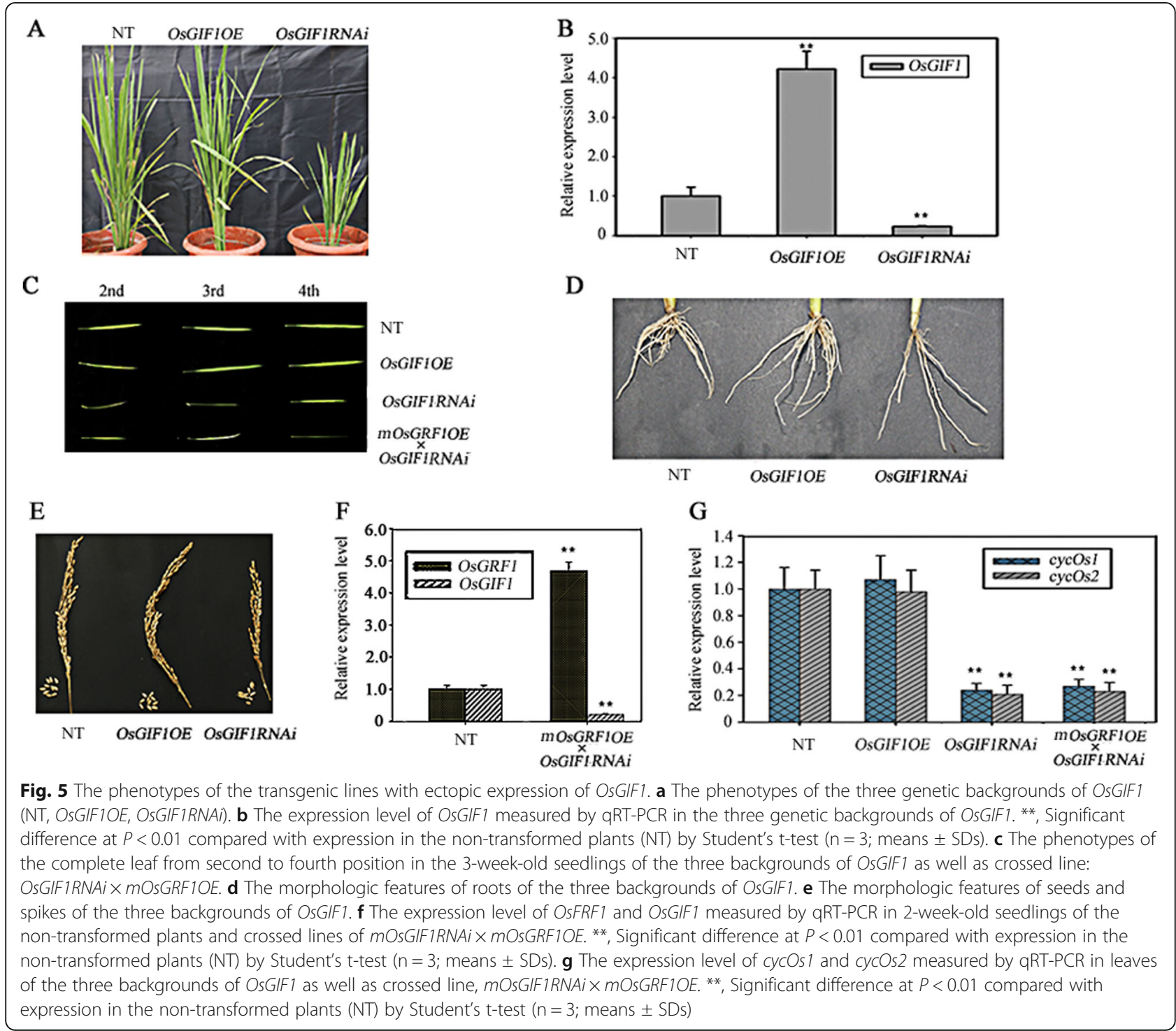


supported by the observation that the size of leaves still exhibited as shrunk in the crossed lines of mOsGRF1OE and OsGIF1RNAi (Fig. 5c), because only overexpression of $m O s G R F 1$ but lack the partner of OsGIF1 is not enough to promote leaf growth. This observation was also supported by molecular evidence that the expression of $c y c O-$ sland cycOs2 were still significantly lower in the leaves of hybrid lines of $m O s G R F 1 O E$ and OsGIF1RNAi (Fig. 5g), in which the expression of OsGRF1 is higher while that of OsGIF1 is lower (Fig. 5f).

\section{Discussion}

The roles of GRF-GIF duo have been revealed to be involved in many aspects of plant development and growth $[15,31]$. However, compared with GIF family which usually comprises very few members, the GRF family is much bigger. So, the diverse functions of GRFs involving many aspects of plants development may reflect the combinations of the specific individual role of different family members. The roles of single member of GIFs seemed to be more versatile due to very fewer members in this family. GIF family found in most eukaryotic species is more conserved than GRF family [17], indicating they may have other roles beyond combination with GRFs. The observation that Arabidopsis gif1/2/3 triple mutant displayed severe defects in the growth and development [22] further supports this assumption. So far, most studies focused on revealing the roles of individual member of the two families but not on the distinct roles of the different combinations [7, 24, 26, 30, 45, 48, 52]. Currently, the precise correlation between the individual members of the two families remains largely unclear.

Here we elaborately compared the expression patterns of OsGRF1 and OsGIF1 and profoundly analyzed the overlap of the phenotypes of transgenic plants with ectopic expression of OsGRF1 and OsGIF1. From our results we can draw the key points as the following.

(1) The expression of OsGIF1 is in a constitutive manner with much higher levels while the expression levels of OsGRF1 are in a tissue-specific preference with relative lower levels overall (Fig. 1). The reasons for higher expression level of OsGIF1 are likely caused by two aspects: the lower copies of OsGIFs (only two in rice) in this family and the assumptions that GIFs also probably interact with other transcription factor, in addition to GRFs, based on some ChIP assays [45, 52];

(2) The specific roles of OsGRF1 may only be involved in regulating leaf growth while the roles of OsGIF may be involved in various aspects of plants growth. To explore the roles of OsGRF1, which prefers to express in tips of both stem and leaf, we use its native promoter rather than a constitutive promoter because we did not intend to sabotage its inherent expression way. The specific role of OsGRF1 in regulating leaf growth was manifested due to avoid being targeted by miR396 (Fig. 3c and d). Additionally the observation that shrunk size of leaves also emerged in the lines of knockdown of OsGRF1 by RNAi, further suggesting its role in regulating leaf growth (Fig. 4b). However the phenotype of knockdown of OsGIF1 displayed multiple defects including shrunk leaves, indicating it may have multiple roles in plant growth (Fig. 5c to e). For reasons why overexpression of OsGIF1 had no new phenotype, we speculated this would be caused by the fact that the expression of OsGIF1 is already in an excessive manner in various tissues (Fig. $1 \mathrm{~b}$ and c);

(3) The expression of OsGRF1 can be affected by various stresses and some kinds of hormones while that of OsGIF1 is unaffected. The expressions of cell-cycle-related genes such as $c y c O s$ land $c y c O s 2$ in rice leaf are under control of OsGIF1-OsGRF1 duo. Even OsGRF1 and cell-cycle-related genes such

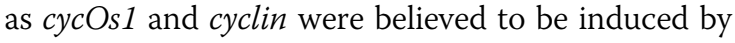
GA [6, 38, 39, 43, 44], but it remained unknown whether there is a link between OsGRF1 and cellcycle-related genes in GA response. Here we suggest that $c y c O s 1$ and $c y c O s 2$ are in the downstream of OsGRF1 in response to GA because higher level of OsGRF1 promoted the expression of cycOs1and cycOs2 while lower level of OsGRF1 inhibited them (Fig. 4e). Even OsGIF1 did not respond to GA (Fig. 2a), the fact that OsGRF1 can interact with OsGRF1 and OsGRF1RNAi also presented a phenotype of shrunken leaves (Fig. 5c), indicating that the expression of $c y c O s 1$ and $c y c O s 2$ may need OsGIF1-OsGRF1 duo.

In summary, here we probed into the distinct role of a combination between the given members of OsGRFs and OsGIFs, and found their specific function in regulating leaf growth. The future studies may probably focus more on revealing the distinct roles of different combinations of OsGRFs and OsGIFs.

\section{Conclusions}

Based on the above results, we propose a working model here to interpret how OsGRF1 and OsGIF1 work together in regulating growth (Fig. 6). We suggest that the expression of OsGRF1 is suppressed by various stresses, ABA, and miR396 while promoted by GA. The interaction between OsGRF1 and OsGIF1 is necessary in specifically promoting leaf growth by promoting the expression of cell-cycle-related genes. However, OsGIF1, 


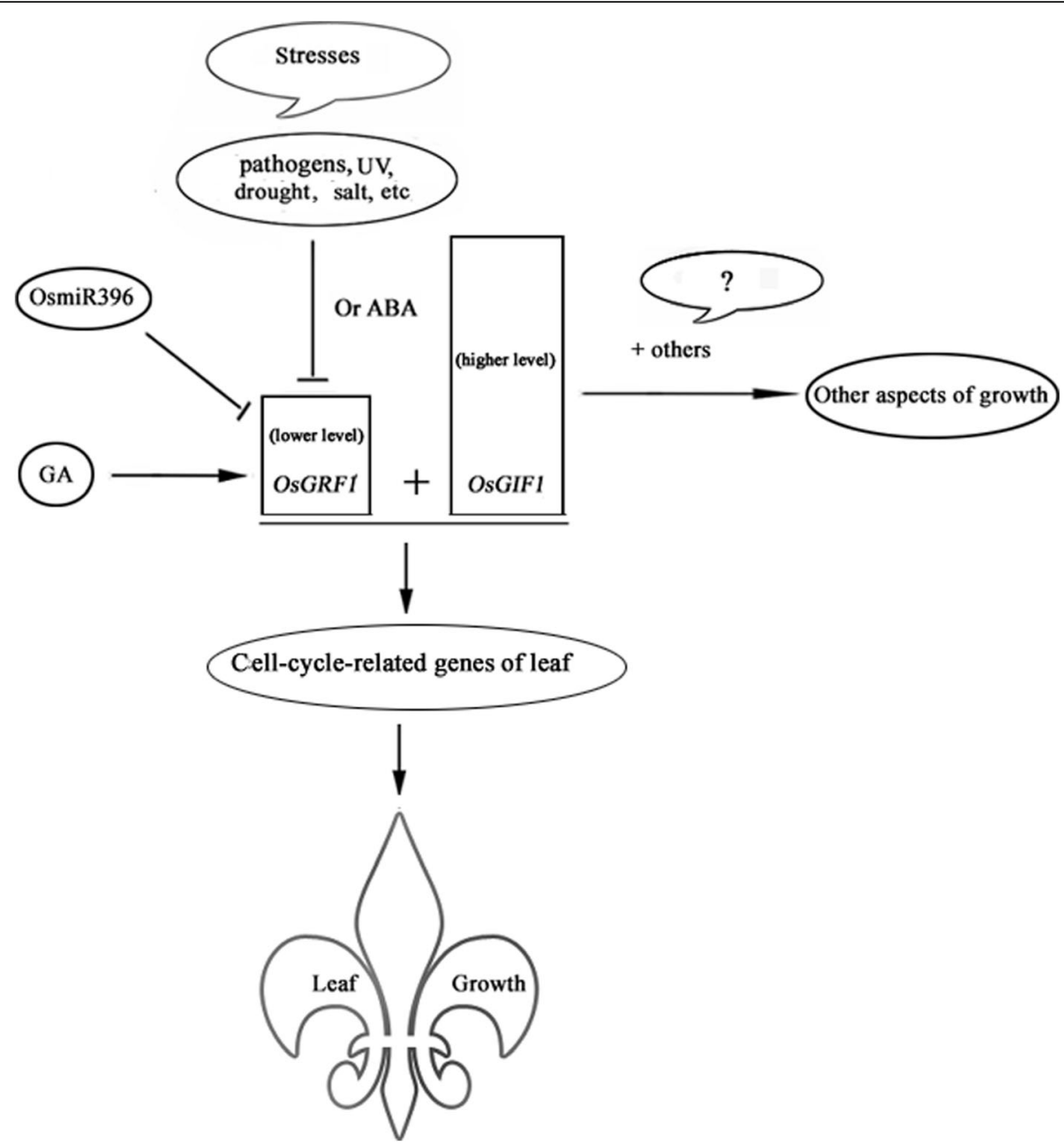

Fig. 6 Model for the functions of OSGRF1 and OsGIF1 in regulating growth. ABA, OsmiR396, and various stresses such as pathogens, ultraviolet (UV), drought, salt, etc., can downregulate the expression of OsGRF1, which is usually in a lower level, while gibberellin (GA) upregulates it. The interaction between OsGRF1 and OSGIF1 is necessary in promoting leaf growth via promoting the expression of cell-cycle-related genes. OsGIF1, which expresses in a higher level, may also work with other factor(s) to regulate other aspects of growth

which expresses in a higher level, may also work with other factor(s) in regulating other aspects of growth.

\section{Methods}

\section{Plant materials and growth conditions}

Rice cultivar (Oryza sativa ssp. japonica) was used as the control plants and serves the genetic background for all transgenic plants. All seeds involved in this study were taken from Key Laboratory of Plant Functional Genomics of the Ministry of Education, Yangzhou University, China. Y.L. undertook the formal identification of the plant materials used in his study. The voucher specimen of this material has not been deposited in a publicly available herbarium yet. The conditions for normal growth of the control plants and transgenic plants were performed as described by Lu et al. [28].

\section{Stress and hormone treatments}

Salt stress, UV light stress, pathogen (Magnaporthe grisea) stress, drought stress, and abscisic acid (ABA) treatment, were performed as described previously [28]. For gibberellin (GA) treatment, the whole 2-week-old seedlings were incubated into N6 liquid solution containing $50 \mu \mathrm{M} \mathrm{GA}_{3}$ and $0.02 \%$ Tween 20 . Then total RNA was extracted from the above seedlings at the point of designated time for genes analysis.

\section{Observation of cells and creation of suspension-cultured cells}

For creation of suspension cells, the rice calli derived from sterilized leaves of the non-transformed plants, OsGRF1OE, and mOsGRF1OE lines were grown on N6 culture medium (solid). Four weeks later, $1 \mathrm{~g}$ of the fresh calli from different lines was incubated into $500 \mathrm{~mL}$ AA 
medium [41] and biomass was measured at given intervals. The suspension cells were observed and recorded under microscope.

\section{Quantitative RT-PCR}

For quantitative RT-PCR analysis of OsGRF1 (Gene ID: Os02g0776900), OsGIF1 (Gene ID: Os03g52320), cycOs1 (Gene ID: Os04g0563700) and cycOs2 (Gene ID: Os06g0726800), $2 \mu \mathrm{g}$ of total RNA was reversely transcribed in a total volume of $20 \mu \mathrm{L}$ with $0.5 \mathrm{mg}$ oligo (dT) $15, \quad 0.75 \mathrm{mM}$ dNTPs, $10 \mathrm{mM}$ DTT, and $100 \mathrm{U}$ SuperScript II RNase H2 reverse transcriptase (Invitrogen). The reaction volume for PCR was $20 \mu \mathrm{L}$ with $1 \mu \mathrm{L}$ of the RT reactions [28]. The primers for quantitative RT-PCR are listed as the following: OsGRF1, FW: $5^{\prime}$ TGATCTTTCAAAAGAGGACGACG-3', RV: 5' TGGTGGTGATCGGGAGGTCGTT-3'; OsGIF1, FW: 5'-GCAGCAGCAGCAGGCGGCGGC-3', RV: 5'TGCCCTTGAGGTACTCCCCGT-3'; cycOs1: FW: 5'GTGTTCTAGGATGATGGTAGA-3', RV: 5' GTTGTAACCTCCTGCTCCTGACT-3', cycOs2: FW: 5'-CATGAGAAGGTTCCTCAAGGCT-3', RV: 5' TGGTGCACTGAGCAGTGTAGA-3'; 30 cycles for PCR was performed and the expression levels of the samples were normalized by OsUbiquitin gene (Forward: 5'-AACCAGCTGAGGCCCAAGA-3', Reverse: 5' -AACCAGTCCATGAACCCGG-3'). Experiments were performed with three biological replicates, of which each was performed in three technical replicates.

\section{Northern-blot analysis}

Total RNA was extracted from different tissues by using TRIzol reagent (Invitrogen). The DNA oligonucleotides of 5'-CAGTTCAAGAAAGCTGTGGAA-3' served as probe for miR396, 5'-ATTTCTCGATTTGT GCGTGTC-3' for U6; The two probes were labeled with $\gamma^{-}{ }^{32} \mathrm{P}$-ATP at $5^{\prime}$ terminal. For mRNA gel-blot analysis, The gene-specific probes for OsGRF1and OsGIF1 were prepared by PCR amplification of genomic DNA that corresponded to the $3^{\prime}$ sequences of cDNA of the two genes and labeled with radioactive ${ }^{32} \mathrm{P}\left(\alpha-{ }^{32} \mathrm{P}-\mathrm{dCTP}\right)$. The two probes were designated to contain same content of radioactive ${ }^{32} \mathrm{P}$ by designed primers (OsGRF1, FW: 5'-TGATCTTTCAAAAGAGGACGACG-3'; RV: 5'-TGGTGGTGATCGGGAGGTCGTT-3'; OsGIF1, FW: 5'-GCAGCAGCAGCAGGCGGCGGC-3'; RV: 5'TGCCCTTGAGGTACTCCCCGT-3'). The process was performed as described previously [28].

\section{Construction of expression vector and generation of transgenic rice lines}

The wild-type OsGRF1 was firstly cloned by RT-PCR with primer as the following: FW: AAGGATCCCAGAGATGATGATGATGAGCGGTCG; RV: GCGAGC
TCAGATTAATCATGCGgGAGgTGGTG. Then the miR396-resistant version of GRF1 ( $m G F F 1$ ) was obtained by using mutagenic primers (FW: 5' - AAGCAC ATGCACCGTGGCAAGAACCGATCTAGAAAACC GGTGGAGATGTCCTTGGCCAC-3'; RV: 5' CAAGGACATCTCCACCGGTTTTCTAGATCGGTTC TTGCCACGGTGCATGTGCTTCTCGCAGTAC-3'). During process of mutation, the first-round PCR products were purified and used as a template for the second amplification. The resulting product was then digested and cloned into pUC18 and the positive clone was verified by sequencing. Finally, both mutated and wild-type OsGRF1 were brought into pCAMBIA1301 in which the original Ubi1 promoter was replaced by the promoter of OsGRF1. The full length of OsGIF1 was cloned by the RT-PCR with primers as the following: FW: 5'-ATGCAGCAGCAACACCTGATGC-3'; RV: 5'-CTAGCT GCCTTCCTCCTCGGT-3'. The OsGIF1 was then constructed into pCAMBIA1301 under Ubi1 promoter for overexpression. For RNAi (RNA interference) of both OsGRF1 and OsGIF1, the specific regions (probe region for northern blot) of the two genes were used for silencing the targets and were brought into pCAMBIA1301 forward and backward respectively, separated by an intron. All the constructed expression vectors were introduced into rice calli through Agrobacterium tumefaciens (EHA105) mediated methods [12].

\section{Western blot}

For western blot of OsGRF1 and OsGIF1, total protein from the 2-week-old seedlings of the non-transformed plants was extracted by SDS sample buffer and boiled for $10 \mathrm{~min}$. Then the extracted proteins were separated by SDS-PAGE and immunoblotted with antibody of anti-OsGRF1 and anti-OsGIF1 at 1:1000 dilution.

To prepare the antibodies of OsGRF1 and OsGIF1, $6 \times$ His-OsGIF1 and $6 \times$ His-OsGRF1 constructed into pET28 vector were expressed and used as antigens to produce monoclonal antibodies in rabbits (Purchased from Junhui Biotech, Co, China). During the process of making monoclonal antibodies, the rabbits were immunized four times at least and the purities of the extracted antibodies should be kept greater than $90 \%$. Finally, the values of enzyme linked immunosorbent assay (ELISA) should be greater than 1:128000.

\section{Abbreviations \\ ABA: Abscisic acid; GRFs: Growth-regulating factors; GIFs: GRF-Interacting Factors; NLS: Nuclear localization signal; qRT-PCR: Quantitative Reverse- Transcription Polymerase-Chain-Reaction; SAM: Shoot Apical Meristem; RNAi: RNA interference}

\section{Acknowledgements}

We thank Dr. Qian-Feng Li for her contribution of expression vector PCAMBIA1301 (also for RNAi). 


\section{Authors' contributions}

YL performed most work of gene expression. YM, JZ and SG took charge of cloning genes as well as constructing vectors. ZF and LB completed most work on transforming rice. YL analyzed data and wrote the article. The authors reviewed and approved the final submission.

\section{Funding}

This work is supported by the National Natural Science Foundation of China (Grant No. 31271623). The founder didn't play any roles in the design, analysis, interpretation of this study and relevant data.

\section{Availability of data and materials}

The datasets generated and analyzed during the current study are available from the corresponding author on reasonable request. Sequence data from this article can be found from the database (http://www.ricedata.cn/gene/) under the following gene ID's/accession numbers: OsGRFI (Os02g0776900), OsGIF1 (Os03g52320), cycOs1 (Os04g0563700) and cycOs2 (Os06g0726800).

\section{Ethics approval and consent to participate}

The plant materials (Oryza sativa L. Nipponbare) used as control and background for all transgenic lines come from Yangzhou University. The experimental research on plants carried out in his work complies with institutional, national, and international guidelines.

\section{Consent for publication}

Not applicable.

\section{Competing interests}

The authors declare that they have no competing interests.

\section{Author details}

'Jiangsu Key Laboratory of Crop Genetics and Physiology/ Key Laboratory of Plant Functional Genomics of the Ministry of Education, Yangzhou University, Yangzhou 225009, China. ${ }^{2}$ Joint International Research Laboratory of Agriculture and Agri-Product Safety, the Ministry of Education of China, Yangzhou University, Yangzhou 225009, Jiangsu, China. ${ }^{3}$ College of Bioscience and Biotechnology, Yangzhou University, Yangzhou 225009, China.

\section{Received: 4 December 2019 Accepted: 29 April 2020}

Published online: 08 May 2020

\section{References}

1. Axtell MJ, Bartel DP. Antiquity of microRNAs and their targets in land plants. Plant Cell. 2005;17:1658-73

2. Baloglu M. Genome-wide in silico identification and comparison of growth regulating factor (GRF) genes in Cucurbitaceae family. Plant Omi J. 2014;7: 260-70.

3. Bao M, Bian H, Zha Y, Li F, Sun Y, Bai B, et al. MiR396a-mediated basic helixloophelix transcription factor bHLH74 repression acts as a regulator for root growth in Arabidopsis seedlings. Plant Cell Physiol. 2014;6:1343-1353.

4. Bazin J, Khan GA, Combier JP, Bustos-Sanmamed P, Debernardi JM, Rodriguez $R$, et al. miR396 affects mycorrhization and root meristem activity in the legume Medicago truncatula. Plant J. 2013;74:920-34

5. Casadevall R, Rodriguez RE, Debernardi JM, Palatnik JF, Casati P. Repression of growth regulating factors by the microRNA396 inhibits cell proliferation by UV-B radiation in Arabidopsis leaves. Plant Cell. 2013;25:3570-83.

6. Choi D, Kim JH, Kende $H$. Whole genome analysis of the OsGRF gene family encoding plant-specific putative transcription activators in rice (Oryza sativa L.). Plant Cell Physiol. 2004;45:897-904.

7. Debernardi JM, Mecchia MA, Vercruyssen L, Smaczniak C, Kaufmann K, Inzé D, et al. Posttranscriptional control of GRF transcription factors by microRNA miR396 and GIF co-activator affects leaf size and longevity. Plant J. 2014;79:413-26.

8. Filiz E, Koc I, Tombuloglu H. Genome-wide identification and analysis of growth regulating factor genes in Brachypodium distachyon: in silico approaches. Turkish J Biol. 2014;38:296-306.

9. Gao P, Bai X, Yang L, Lv D, Li Y, Cai H, et al. Over-expression of Osa-MIR396c decreases salt and alkali stress tolerance. Planta. 2010;231:991-1001.

10. He Z, Zeng J, Ren Y, Chen D, Li W, Gao F, et al. OsGIF1 positively regulates the sizes of stems, leaves, and grains in Rice. Front Plant Sci. 2017;8:1730.
11. Hewezi T, Maier TR, Nettleton D, Baum TJ. The Arabidopsis microRNA396GRF1/GRF3 regulatory module acts as a developmental regulator in the reprogramming of root cells during cyst nematode infection. Plant Physiol. 2012:159:321-35.

12. Hiei $Y$, Ohta S, Komari T, Kumashiro T. Efficient transformation of rice (Oryza sativa L.) mediated by agrobacterium and sequence analysis of the boundaries of the T-DNA. Plant J. 1994;6(2):271-82.

13. Horiguchi G, Kim G, Tsukaya H. The transcription factor AtGRF5 and the transcription coactivator AN3 regulate cell proliferation in leaf primordia of Arabidopsis thaliana. Plant J. 2005;43:68-78.

14. Jones-Rhoades MW, Bartel DP. Computational identification of plant microRNAs and their targets, including a stress-induced miRNA. Mol Cell. 2004;14 787-99.

15. Kim JH. Biological roles and an evolutionary sketch of the GRF-GIF transcriptional complex in plants. BMB Rep. 2019:52(4):227-38.

16. Kim JH, Choi $D$, Kende $H$. The AtGRF family of putative transcription factors is involved in leaf and cotyledon growth in Arabidopsis. Plant J. 2003;36:94104.

17. Kim JH, Kende H. A transcriptional coactivator, AtGIF1, is involved in regulating leaf growth and morphology in Arabidopsis. Proc Natl Acad Sci U S A. 2004;101(36):13374-9.

18. Kim JH, Lee BH. GROWTH-REGULATING FACTOR4 of Arabidopsis thaliana is required for development of leaves, cotyledons, and shoot apical meristem. J Plant Biol. 2006:49:463-8.

19. Kim J-S, Mizoi J, Kidokoro S, Maruyama K, Nakajima J, Nakashima K, et al. Arabidopsis growth-regulating factor7 functions as a transcriptional repressor of abscisic acid- and osmotic stress-responsive genes, including DREB2A. Plant Cell. 2012:24:3393-405.

20. Kuijt SJH, Greco R, Agalou A, Shao J, CJ't Hoen C, Övernäs E, et al. Interaction between the GROWTH-REGULATING FACTOR and KNOTTED1LIKE HOMEOBOX families of transcription factors. Plant Physiol. 2014;164: 1952-66.

21. Lee BH, Ko J-H, Lee S, Lee Y, Pak J-H, Kim JH. The Arabidopsis GRFINTERACTING FACTOR gene family performs an overlapping function in determining organ size as well as multiple developmental properties. Plant Physiol. 2009:151:655-68.

22. Lee BH, Wynn AN, Franks RG, Hwang Y, Lim J, Kim JH. The Arabidopsis thaliana GRF- INTERACTING FACTOR gene family plays an essential role in control of male and female reproductive development. Dev Biol. 2014;386: $12-24$.

23. Li S, Gao F, Xie K, Zeng X, Cao Y, Zeng J, et al. The OsmiR396c-OsGRF4OsGIF1 regulatory module determines grain size and yield in rice. Plant Biotechnol J. 2016:14(11):2134-46.

24. Liang G, He H, Li Y, Wang F, Yu D. Molecular mechanism of microRNA396 mediating pistil development in Arabidopsis. Plant Physiol. 2014;164:249-58.

25. Liu D, Song Y, Chen Z, Yu D. Ectopic expression of miR396 suppresses GRF target gene expression and alters leaf growth in Arabidopsis. Physiol Plant 2009;136:223-36.

26. Liu H, Guo S, Xu Y, Li C, Zhang Z, Zhang D, et al. OsmiR396d-regulated OsGRFs function in floral organogenesis in rice through binding to their targets OsJMJ706 and OsCR4. Plant Physiol. 2014;165:160-74.

27. Liu J, Hua W, Yang H-L, Zhan G-M, Li R-J, Deng L-B, et al. The BnGRF2 gene (GRF2- like gene from Brassica napus) enhances seed oil production through regulating cell number and plant photosynthesis. J Exp Bot. 2012; 63:3727-40

28. Lu Y, Feng Z, Liu X, Bian L, Xie H, Zhang C, et al. MiR393 and miR390 synergistically regulate lateral root growth in rice under different conditions. BMC Plant Biol. 2018;18(1):261.

29. Mecchia MA, Debernardi JM, Rodriguez RE, Schommer C, Palatnik JF. MicroRNA miR396 and RDR6 synergistically regulate leaf development. Mech Dev. 2013;130:2-13.

30. Nelissen H, Eeckhout D, Demuynck K. Dynamic changes in ANGUSTIFOLIA3 complex composition reveal a growth regulatory mechanism in the maize leaf. Plant Cell. 2015:27:1605-19.

31. Omidbakhshfard MA, Proost S, Fujikura U, Mueller-Roeber B. Growthregulating factors (GRFs): a small transcription factor family with important functions in plant biology. Mol Plant. 2015:8:998-1010.

32. Osnato M, Stile MR, Wang Y, Meynard D, Curiale S, Guiderdoni E, et al. Cross talk between the KNOX and ethylene pathways is mediated by intron-binding transcription factors in barley. Plant Physiol. 2010;154: $1616-32$. 
33. Pajoro A, Madrigal P, Muiño JM, Matus JT, Jin J, Mecchia MA, et al. Dynamics of chromatin accessibility and gene regulation by MADSdomain transcription factors in flower development. Genome Biol. 2014;15:R41.

34. Proost S, Van Bel M, Vaneechoutte D, Van de Peer Y, Inze D, Mueller-Roeber B, et al. PLAZA 3.0: an access point for plant comparative genomics. Nucleic Acids Res. 2015;43:D974-81.

35. Rodriguez RE, Ercoli MF, Debernardi JM, Breakfield NW, Mecchia MA, Sabatini M, et al. MicroRNA miR396 regulates the switch between stem cells and transit-amplifying cells in Arabidopsis roots. Plant Cell. 2015;27:3354-66.

36. Rodriguez RE, Mecchia MA, Debernardi JM, Schommer C, Weigel D, Palatnik JF. Control of cell proliferation in Arabidopsis thaliana by microRNA miR396. Development. 2010;137:103-12.

37. Rodriguez RE, Schommer C, Palatnik JF. Control of cell proliferation by microRNAs in plants. Curr Opin Plant Biol. 2016;34:68-76.

38. Sauter M. Differential expression of a CAK (cdc2-activating kinase)-like protein kinase, cyclins and cdc2 genes from rice during the cell cycle and in response to gibberellin. Plant J. 1997;11:181-90.

39. Sauter M, Mekhedovm SL, Kende H. Gibberellin promotes histone $\mathrm{H} 1$ kinase activity and the expression of $c d c 2$ and cyclin genes during the induction of rapid growth in Deepwater rice internodes. Plant J. 1995;7:623-32.

40. Sunkar R, Girke T, Jain PK, Zhu JK. Cloning and characterization of microRNAs from rice. Plant Cell. 2005;17:1397-411.

41. Toriyama K, Hinata K. Cell suspension and protoplast culture in rice. Plant Sci. 1985;41:179-83.

42. Van De Velde K, Ruelens P, Geuten K, Rohde A, Van Der Straeten D. Exploiting DELLA signaling in cereals. Trends Plant Sci. 2017;22:880-93.

43. van der Knaap $\mathrm{E}$, Kende $\mathrm{H}$. Identification of a gibberellin-induced gene in Deepwater rice using differential display of mRNA. Plant Mol Biol. 1995;28: 589-92.

44. Van der Knaap E, Kim JH, Kende H. A novel gibberellin induced gene from rice and its potential regulatory role in stem growth. Plant Physiol. 2000;122: 695-704.

45. Vercruyssen L, Verkest A, Gonzalez N. ANGUSTIFOLIA3 binds to SWI/SNF chromatin remodeling complexes to regulate transcription during Arabidopsis leaf development. Plant Cell. 2014:26:210-29.

46. Wang F, Qiu N, Ding Q, Li J, Zhang Y, Li H, et al. Genome-wide identification and analysis of the growth-regulating factor family in Chinese cabbage (Brassica rapa L. ssp. pekinensis). BMC Genomics. 2014;15:807.

47. Wang L, Gu XL, Xu DY, Wang W, Wang H, Zeng MH, et al. miR396-targeted AtGRF transcription factors are required for coordination of cell division and differentiation during leaf development in Arabidopsis. J Exp Bot. 2011;62: 761-73.

48. Wu L, Zhang D, Xue M, Qian J, He Y, Wang S. Overexpression of the maize GRF10, an endogenous truncated GRF protein, leads to reduction in leaf size and plant height. J Integr Plant Biol. 2014;56:1053-63.

49. Wu L, Zhang Q, Zhou H, Ni F, Wu X, Qi Y. Rice microRNA effector complexes and targets. Plant Cell. 2009;21:3421-35.

50. Xue LJ, Zhang JJ, Xue HW. Characterization and expression profiles of miRNAs in rice seeds. Nucleic Acids Res. 2009;37:916-30.

51. Yang F, Liang G, Liu D, Yu D. Arabidopsis miR396 mediates the development of leaves and flowers in transgenic tobacco. J Plant Biol. 2009; 52:475-81.

52. Zhang D, Sun W, Singh R. GRF-interacting factor1 (gif1) regulates shoot architecture and meristem determinacy in maize. Plant Cell. 2018;30:360-74.

53. Zhang D-F, Li B, Jia G-Q, Zhang T-F, Dai J-R, Li J-S, et al. Isolation and characterization of genes encoding GRF transcription factors and GIF transcriptional coactivators in maize (Zea mays L.). Plant Sci. 2008;175:809-17.

\section{Publisher's Note}

Springer Nature remains neutral with regard to jurisdictional claims in published maps and institutional affiliations.

Ready to submit your research? Choose BMC and benefit from:

- fast, convenient online submission

- thorough peer review by experienced researchers in your field

- rapid publication on acceptance

- support for research data, including large and complex data types

- gold Open Access which fosters wider collaboration and increased citations

- maximum visibility for your research: over $100 \mathrm{M}$ website views per year

At BMC, research is always in progress.

Learn more biomedcentral.com/submissions 